\title{
Postoperative Treatment of Distal Radius Fractures Using Sensorimotor Rehabilitation
}

\author{
Ronit Wollstein, MD ${ }^{1}$ Hani Harel, MA $^{2} \quad$ Idit Lavi, MA \\ ${ }^{1}$ Department of Orthopedic Surgery, New York University, School of \\ Medicine, Huntington Station, New York \\ ${ }^{2}$ Carmel Lady Davis Medical Center Occupational Therapy, Haifa, Israel \\ ${ }^{3}$ Department of Community Medicine and Epidemiology, Carmel \\ Medical Center, Haifa, Israel \\ ${ }^{4}$ Department of Orthopedic Surgery, School of Medicine,Technion- \\ Israel Institute of Technology, Haifa, Israel
}

J Wrist Surg 2019;8:2-9.

\author{
Address for correspondence Ronit Wollstein, MD, Department of \\ Orthopedic Surgery, New York University, School of Medicine, 180 \\ East. Pulaski Road, Huntington Station, NY 11746 \\ (e-mail: ronitwollstein@gmail.com).
}

\begin{abstract}
Keywords

- distal radius fracture

- postoperative

- proprioception

- rehabilitation

- sensorimotor therapy
\end{abstract}

Background Sensorimotor and specifically proprioception sense has been used in rehabilitation to treat neurological and joint injuries. These feedback loops are not well understood or implemented in wrist treatment. We observed a temporary sensorimotor loss, following distal radius fractures (DRF) that should be addressed postsurgery.

Purpose The purpose of this prospective therapeutic study was to compare the outcomes of patients following surgery for DRF treated using a sensorimotor treatment protocol with those patients treated according to the postoperative standard of care. Patients and Methods Patients following surgery for DRF sent for hand therapy were eligible for the study. Both the evaluation and treatment protocols included a comprehensive sensorimotor panel. Patients were randomized into standard and standard plus sensorimotor postoperative therapy and were evaluated a few days following surgery, at 6 weeks, and 3 months postsurgery.

Results Sixty patients following surgery were randomized into the two treatment regimens. The initial evaluation was similar for both groups and both demonstrated significant sensorimotor deficits, following surgery for DRF. There was documented sensorimotor and functional improvement in both groups with treatment. The clinical results were better in the group treated with the sensorimotor-proprioception protocol mostly in the wrist; however, not all of the differences were significant.

Conclusion Patients after surgery for DRF demonstrate significant sensorimotor deficits which may improve faster when utilizing a comprehensive sensorimotor treatment protocol. However, we did not demonstrate efficacy of the protocol in treating proprioceptive deficits. Further study should include refinement of functional outcome evaluation, studying of the treatment protocol, and establishment of sensorimotor therapeutic guidelines for other conditions.

Level of Evidence This is a level II, therapeutic study. received

March 22, 2018

accepted

August 2, 2018

published online

September 27, 2018
Copyright ( $) 2019$ by Thieme Medical

Publishers, Inc., 333 Seventh Avenue, New York, NY 10001, USA.

Tel: +1(212) 584-4662.
DOI https://doi.org/

10.1055/s-0038-1672151. ISSN 2163-3916. 
Although sensorimotor input is not easily defined, much study has been done to try and understand sensorimotor pathways., ${ }^{1,2}$ Specifically, proprioception has been studied extensively, prompting its use in rehabilitation, most commonly to treat neurological and joint injuries. ${ }^{3-5}$ Though many studies support proprioceptive training in the treatment and prevention of ligamentous injuries, some controversy remains in regards to its effectiveness. ${ }^{6-8}$

While our understanding of proprioception in joints such as the knee or ankle has been incorporated into rehabilitation and training techniques, our understanding of wrist proprioception has only recently been elucidated and remains incomplete. ${ }^{9-11}$ We are, therefore, still in the process of formulating ways to best evaluate proprioception in the wrist, and are yet in preliminary stages of learning how to treat wrist ligamentous injuries using proprioceptive training. ${ }^{12-14}$

The evaluation of wrist proprioception has been described using different methods, most commonly, positioning of the injured wrist at different angles and then asking the patient to mimic the angle with the intact wrist without the use of sight. ${ }^{12,15,16}$ While this is a good test of joint position sense, most studies evaluate multiple neurological functions, such as deep vibratory sensation and stereognosis. ${ }^{9,17-19}$ Since all sensorimotor input is integrated centrally, we believe that rehabilitation should include work on different aspects of sensorimotor function for optimal results. ${ }^{20-22}$

Our clinical impression is that patients following a significant period of immobilization loose wrist and hand proprioceptive ability and require proprioception rehabilitation. The reason for this deficiency in distal radius fractures has not been proven and may differ in individual cases. It is possible that this stems from a central loss due to immobilization and lack of sensory input, as described by Taube et al; however, the fracture itself and the consequent surgery often involve damage to wrist joint capsule, ligaments, and possibly other soft tissues, such as tendons and muscles. This may impede sensory input from these structures but also motor output. ${ }^{23,24}$

This observation has been supported in some studies. Avanzino et al demonstrated that in short-term (3 weeks) arm immobilization, maintenance of dynamic proprioceptive inputs from muscle vibration prevent the hemispheric unbalance, induced by short-term limb disuse. ${ }^{25,26}$ Kavounoudias et al demonstrated the effect of sensory stimulation in offsetting the effects of immobilization on functional magnetic resonance imaging. ${ }^{27}$ We used an evaluation and treatment protocol that incorporates multiple sensorimotor domains. This protocol has been employed in a series of patients following surgery for open reduction and internal fixation (ORIF) of distal radius fractures (DRF) with good functional recovery. ${ }^{28}$

The purpose of this study was to prospectively compare the clinical results of patients following surgical treatment for DRFs, treated with a specific sensorimotor protocol to those treated postoperatively without the protocol.

\section{Patients and Methods}

All consecutive adult patients treated surgically for a DRF were eligible for inclusion in the study. Institutional review board (IRB) approval was obtained prior to study commencement. Only patients treated with volar plating were included. All patients were treated according to standard of care in therapy with postoperative orthotics, active and passive exercises for the fingers while immobilized, and after removal of the orthosis at 6 weeks, all began treatment for the wrist. Although some patients could have started early range of motion of the wrist, for purposes of the study, all patients were instructed to use an orthosis for a full 6 weeks. An evaluation was not performed prior to surgery because the patients had an acute fracture and it was deemed too painful to perform. Furthermore, evaluation in this situation might yield unpredictable results. The patients were randomized prior to evaluation into a group, treated according to standard of care with an added sensorimotor home protocol, according to a list. The patients were instructed to perform the home protocol three times a day for 15 minutes. IRB approval was obtained prior to the study commencement.

Sensorimotor evaluation was performed and documented in all patients during the first couple of days post surgery: at 6 weeks (at the time of splint removal) and 3 months following surgery. Since 48 patients (80\%) had an ultrasound-guided regional block for anesthesia, the initial evaluation was not performed immediately following surgery but rather within the first 5 days of surgery when the effects of the anesthesia had clearly worn off.

Patient information was collected including age, gender, hand dominance, injured hand, occupation, background, disease-especially diabetes, and other neurological disease, inflammatory disease, fracture type, and comminution according to the Arbeitsgemeinschaft für Osteosynthesefragen (AO) classification, any complications, range of motion, and grip strength at 6 weeks and 3 months.

\section{The Evaluation}

Testing included a panel of sensorimotor testing. ${ }^{28}$ This included blinded sensory testing with Semmes-Weinstein monofilaments (Sammons Preston, Bolingbrook, IL), static and moving 2-point discrimination, vibration, temperature, the Moberg's pick-up test (timed), stereognosis, and proprioception. ${ }^{29,30}$

The testing for proprioception, as described, requires sensory input first, or an afferent portion, and then, when bringing the opposite limb into the same position there is a motor or efferent component. This test, therefore, involves both the involved and the uninvolved side (as the afferent and efferent limbs of the movement). Since we were unable to separate the components, we did not compare the involved to the uninvolved side in proprioception. Furthermore, to simplify the analysis, all abnormal values for proprioception were pooled and the analysis did not differentiate between proprioception in individual fingers and the wrist.

Vibration was documented as normal or abnormal. Chronic regional pain syndrome (CRPS) in its early stages was defined as patients seen in therapy with an increasing pain, an unwillingness to move or work with the involved hand, and the very beginning of trophic changes, such as a change in color. This was documented in the patient chart by the treating therapist. 
Table 1 The home sensorimotor protocol

\begin{tabular}{|l|}
\hline Home Protocol 15 min $\times 2$ each day \\
\hline $\begin{array}{l}\text { - Sensory stimulation-each finger from distal to } \\
\text { proximal with and without cream }\end{array}$ \\
\hline $\begin{array}{l}\text { - Flexion and extension-each finger active and passive } \\
\text { using the uninjured hand-eyes open and eyes closed }\end{array}$ \\
\hline - Adduction and abduction fingers-eyes open and closed \\
\hline - Mirror imaging of finger movement 1-5 \\
flexion/extension abduction-eyes open and eyes closed \\
\hline - Stimulation of each finger with different textures \\
(cotton. steel wool, toothbrush)-eyes open and \\
eyes closed \\
\hline - Imagination with eyes closed wrist flexion/extension, \\
radio-ulnar deviation and pro-supination \\
\hline - Same movement-both wrists \\
\hline - Activities of daily living (AOL)-eyes open and eyes \\
closed
\end{tabular}

\section{Therapeutic Protocol}

Therapy sessions were performed (in both groups) once a week for about an hour. The patients worked on movement, activities of daily living (ADL), and edema control as well as orthosis adjustment as necessary. After 6 weeks, with removal of the orthosis, the patients commenced work on the wrist with motion, both active and passive, and gradual strengthening, as well as continuing work on ADL.

The home protocol has been described in - Table $1 .^{28}$ This protocol includes sensory stimulation, activities of daily living, performed with eyes closed, and exercises to improve proprioception by first performing a task with the uninjured wrist/hand, and then imitating it with the injured extremity. This is done with eyes closed and corrected with eyes open. Furthermore, the patients used mirror therapy and while the wrist was splinted, they imagined the wrist moving during exercise. For those patients that had difficulty with imagination, the therapists encouraged more mirror therapy to try and work on the wrist at a more "automatic" level. ${ }^{31}$

\section{Statistical Analysis}

Analysis included the paired $t$-test or Mann-Whitney test to compare continuous outcome measures, such as range of motion and grip strength between the two treatment groups. Fisher's exact test and chi-squared test for categorical variables. McNemar's test was used for vibration calculations (paired nominal data: abnormal/normal).

\section{Results}

Sixty patients were included in the study, 31 in the standard group and 29 in the protocol group. The two groups did not differ in regards to patient or fracture characteristics. - Table 2 describes the study population.
Table 2 Population characteristics

\begin{tabular}{|l|l|l|l|}
\hline Test & $\begin{array}{l}\text { Standard } \\
\text { treatment } \\
\text { group, } \\
\mathbf{n = 3 1}\end{array}$ & $\begin{array}{l}\text { Protocol } \\
\text { treatment } \\
\text { group, } \\
\mathbf{n = 2 9}\end{array}$ & $p$-Value \\
\hline Age, y (SD) & $63.9(17.0)$ & $62.3(18.0)$ & 0.71 \\
\hline $\begin{array}{l}\text { Gender }=\text { female } \\
n(\%)\end{array}$ & 67.7 & 85.7 & 0.11 \\
\hline $\begin{array}{l}\text { Hand dominance }= \\
\text { right (\%) }\end{array}$ & 87.1 & 89.7 & 1.00 \\
\hline $\begin{array}{l}\text { Dominant hand }= \\
\text { injured hand (\%) }\end{array}$ & 41.9 & 51.7 & 0.46 \\
\hline Osteoporosis (\%) & 71.0 & 72.4 & 0.90 \\
\hline $\begin{array}{l}\text { AO classification } \\
\text { (C2, C3; \%) }\end{array}$ & 54.8 & 62.1 & 0.06 \\
\hline
\end{tabular}

Abbreviation: AO, Arbeitsgemeinschaft für Osteosynthesefragen; SD, standard deviation.

Note: The two groups were comparable in regard to patient and fracture characteristics. Both groups included approximately $70 \%$ of fragility fractures and most surgically treated fractures were comminuted and intra-articular.

On initial evaluation, we found sensorimotor deficiencies in the injured hand in both groups, when compared with the uninjured hand or established norms (-Tables 3 and 4). The Disabilities of the Arm, Shoulder, and Hand (DASH) score for the group as a whole was 67.14 (standard deviation [SD] $=22.7$ ). The deficiencies were most pronounced in the Moberg's pick-up test, stereognosis, and in proprioception (-Table 3). There were significant differences between the two groups at initial evaluation in static moving 2-point discrimination of the distal phalanx of the little finger $(0.02)$ and in the moving 2-point discrimination of the distal phalanx of the index finger (0.05). There were no significant differences in sensation between the areas innervated by the ulnar nerve and median nerves (-Table 4). Temperature evaluation for both cold and hot sensation was normal at initial evaluation, in both groups.

Vibration was abnormal in a large percentage of the population as a whole and did not improve significantly with treatment. We observed that some of the patients had increased vibration sense, which was most pronounced at initial evaluation. Out of 620 vibration measurements (including 30 and $256 \mathrm{~Hz}$ and all positions and patients) 128 documented increased sensitivity to vibration $20.6 \%$.

There was no significant difference between the groups in range of motion (ROM) of the fingers, thumb and wrist at the initial evaluation. Both treatment groups improved from the 6-week evaluation to final evaluation at 3 months (-Table 5). At 3 months, the protocol group had improved more than the standard treatment group in all measured movements, but this difference was significant only in radial and ulnar deviation (-Table 5). Grip strength improved significantly in both groups.

The sensorimotor tests improved from initial evaluation to final evaluation at 3 months, in both groups. The difference in improvement was significantly better (larger) in the protocol 
Table 3 Initial sensorimotor deficits-comparison between the two groups

\begin{tabular}{|l|l|l|l|}
\hline & $\begin{array}{l}\text { Standard treatment } \\
\text { group injured } \\
\text { noninjured, } \\
n=31\end{array}$ & $\begin{array}{l}\text { Protocol treatment } \\
\text { group injured/ } \\
\text { noninjured, } \\
n=29\end{array}$ & $p$-Value \\
\hline $\begin{array}{l}\text { Semmes-Weinstein distal phalanx thumb (mean) } \\
\text { median }\end{array}$ & $\begin{array}{l}1.08(0.16) \\
1.00\end{array}$ & $\begin{array}{l}1.09(0.14) \\
1.00\end{array}$ & 0.91 \\
\hline $\begin{array}{l}\text { Static 2 point distal phalanx thumb (mean) } \\
\text { median }\end{array}$ & $1.12(0.56)$ & $1.12(0.33)$ & 0.34 \\
\hline Moving 2 point distal phalanx thumb (mean) & 1.00 & 1.00 & 0.66 \\
median & 1.00 & $1.07(0.35)$ & 0.64 \\
\hline Moberg's pick-up test eyes closed (s) & $2.45(1.01)$ & $2.21(0.79)$ & 0.79 \\
\hline Moberg's pick-up test eyes open (s), SD & $2.55(1.10)$ & $2.89(1.85)$ & 0.38 \\
\hline Stereognosis \% abnormal (SD) & $23(85.2)$ & $24(82.8)$ & 0.06 \\
\hline DASH score & $72.9(19.9)$ & $61.4(22.7)$ & 0.65 \\
\hline Proprioception thumb involved, $n$ (\% abnormal) & $12(38.7)$ & $10(35.7)$ & $9(40.9)$ \\
\hline Proprioception fingers all involved, $n$ (\% abnormal) & $12(40.0)$ & $2(7.4)$ & 0.14 \\
\hline Proprioception wrist involved, $n$ (\% abnormal) & $6(19.4)$ & 0.28 \\
\hline
\end{tabular}

Abbreviation: DASH, disabilities of the arm, shoulder, and hand; SD, standard deviation.

Notes: DASH outcome questionnaire. There were no differences between our two groups at initial evaluation ( $p$-values), but there were significant deficiencies in sensorimotor testing in the group as a whole.

Stereognosis and proprioception could not be compared with the uninjured side so were documented as percent (\%) abnormal results. The DASH score is listed as a number $(0-100)$.

treatment group as compared with the standard treatment group in Semmes-Weinstein testing of the wrist $(p=0.03)$, static 2 -point discrimination in the index $(p=0.03)$, and little fingers $(p=0.008)$.

Moberg's pick-up testing with eyes open and closed improved significantly $(p=0.02, p=0.05)$, only in the protocol group. Stereognosis improved in the protocol group from $24 \%$ with an abnormal test at initial evaluation to $0 \%$ at 3 -month evaluation, while the standard group improved from 14 to $0 \%$. At 6 weeks, there were $0 \%$ abnormal tests in the protocol group and $6 \%$ in the standard treatment group.

Although no patients developed full blown chronic regional pain syndrome (CRPS), there were four cases of documented initial signs and symptoms of CRPS. All of these were in the standard treatment group.

The DASH score improved significantly in the protocol group only $p=0.00$. At 3 months, the mean was 33.7 (22.0) in the standard group and 21.3 (17.4) in the protocol group.

Proprioception deficits were pronounced at initial evaluation and remained high at 6 weeks and at 3 months, though there was consistent improvement in all, but the wrist parameters. At 6 weeks there was a trend toward significance in wrist proprioception between the two groups. Both groups had increased proprioception deficits, when compared with the initial evaluation, but the protocol group had less of an increase: the standard group had 10 patients (55.6\%) with abnormal testing, the protocol group had eight patients $(28.6 \%)$ with abnormal results $p=0.07$. There were no other significant differences in improvement between the two groups at 3 months (-Table 6 ).
The treating therapists had a (unmeasured and likely biased) sense that patients treated with the protocol had better overall function and earlier use of both hands for everyday function.

\section{Discussion}

This study found significant initial sensorimotor deficits in a population of patients being treated in therapy following ORIF of DRF. The use of a protocol aimed at improving sensorimotor function seemed to improve function faster than standard postoperative therapy. This was demonstrated objectively in multiple measured functional scores. The improvement in sensorimotor testing at 3 months in the treated group is in tandem with the results of sensorimotor re-education. ${ }^{32,33}$

We did not find a significant improvement in proprioception, despite using a protocol, aimed at treating proprioceptive loss. On the contrary, we saw a trend toward increase in wrist proprioception deficit at 6 weeks. This evaluation was performed following 6 weeks of wrist immobilization (for all patients) and despite treatment, the impairment increased in both groups. This increase may be explained by a longer period of immobilization. Since at initial evaluation, patients had variable and much shorter periods of immobilization prior to surgery and consequent testing, it is possible that further restriction increased the deficits.

We did see a weak trend toward better proprioception (less of an increase in deficit) using the protocol. Although this may support its use in rehabilitation, we were unable to prove its effectiveness. We also do not know, how long the 
6 Sensorimotor Treatment for Distal Radius Fractures Wollstein et al.

Table 4 Initial sensorimotor testing fingers

\begin{tabular}{|c|c|c|c|c|c|c|}
\hline & $\begin{array}{l}\text { Standard } \\
\text { treatment } \\
\text { group, } n=30\end{array}$ & $\begin{array}{l}\text { Protocol } \\
\text { treatment } \\
\text { group, } n=29\end{array}$ & $\begin{array}{l}p \text {-Value } \\
\text { (involved) }\end{array}$ & $\begin{array}{l}\text { Standard } \\
\text { treatment } \\
\text { group injured/ } \\
\text { noninjured, } \\
n=30\end{array}$ & $\begin{array}{l}\text { Protocol } \\
\text { treatment } \\
\text { group Injured/ } \\
\text { noninjured } \\
n=29\end{array}$ & $\begin{array}{l}p \text {-Value } \\
\text { injured/ } \\
\text { uninjured }\end{array}$ \\
\hline $\begin{array}{l}\text { Semmes-Weinstein } \\
\text { distal phalanx index } \\
\text { finger mean (SD) } \\
\text { median }\end{array}$ & $\begin{array}{l}3.42(0.74) \\
3.61\end{array}$ & $\begin{array}{l}3.50(0.49) \\
3.61\end{array}$ & 0.25 & $\begin{array}{l}1.06(0.14) \\
1.00\end{array}$ & $\begin{array}{l}1.08(0.23) \\
1.00\end{array}$ & 0.15 \\
\hline $\begin{array}{l}\text { Semmes-Weinstein } \\
\text { distal phalanx little } \\
\text { finger mean (SD) } \\
\text { median }\end{array}$ & $\begin{array}{l}3.30(0.44) \\
3.61\end{array}$ & $\begin{array}{l}3.38(0.57) \\
3.61\end{array}$ & 0.43 & $\begin{array}{l}1.03(0.15) \\
1.0\end{array}$ & $\begin{array}{l}1.02(0.09) \\
1.0\end{array}$ & 0.82 \\
\hline $\begin{array}{l}\text { Static 2-point distal } \\
\text { phalanx index finger } \\
\text { mean (SD) } \\
\text { median }\end{array}$ & $\begin{array}{l}0.67(0.21) \\
0.60\end{array}$ & $\begin{array}{l}0.70(0.40) \\
0.50\end{array}$ & 0.46 & $\begin{array}{l}1.20(0.48) \\
1.0\end{array}$ & $\begin{array}{l}0.97(0.30) \\
1.0\end{array}$ & 0.10 \\
\hline $\begin{array}{l}\text { Static 2-point distal } \\
\text { phalanx little finger } \\
\text { mean (SD) } \\
\text { median }\end{array}$ & $\begin{array}{l}0.72(0.3) \\
0.60\end{array}$ & $\begin{array}{l}0.72(0.4) \\
0.50\end{array}$ & 0.34 & $\begin{array}{l}1.20(0.30) \\
1.0\end{array}$ & $\begin{array}{l}1.01(0.30) \\
1.0\end{array}$ & 0.02 \\
\hline $\begin{array}{l}\text { Moving 2-point distal } \\
\text { phalanx index finger } \\
\text { mean (SD) } \\
\text { median }\end{array}$ & $\begin{array}{l}0.69(0.21) \\
0.60\end{array}$ & $\begin{array}{l}0.64(0.27) \\
0.50\end{array}$ & 0.17 & $\begin{array}{l}1.17(0.40) \\
1.0\end{array}$ & $\begin{array}{l}0.96(0.27) \\
1.0\end{array}$ & 0.05 \\
\hline $\begin{array}{l}\text { Moving 2-point distal } \\
\text { phalanx little finger } \\
\text { mean (SD) } \\
\text { median }\end{array}$ & $\begin{array}{l}0.74(0.29) \\
0.60\end{array}$ & $\begin{array}{l}0.67(0.31) \\
0.50\end{array}$ & 0.07 & $\begin{array}{l}1.24(0.49) \\
1.00\end{array}$ & $\begin{array}{l}0.99(0.34) \\
1.00\end{array}$ & 0.007 \\
\hline $\begin{array}{l}\text { Vibration } 256 \mathrm{~Hz} \\
\text { index finger } \\
\text { (\% normal) }\end{array}$ & 75.0 & 86.7 & 1.0 & - & - & - \\
\hline $\begin{array}{l}\text { Vibration } 256 \mathrm{~Hz} \\
\text { little finger } \\
\text { (\% normal) }\end{array}$ & 42.9 & 60.0 & 0.8 & - & - & - \\
\hline $\begin{array}{l}\text { Vibration } 30 \mathrm{~Hz} \\
\text { index finger } \\
\text { (\% normal) }\end{array}$ & 81.8 & 81.3 & 1.0 & - & - & - \\
\hline $\begin{array}{l}\text { Vibration } 30 \mathrm{~Hz} \\
\text { little finger } \\
\text { (\% normal) }\end{array}$ & 42.9 & 69.2 & 0.3 & - & - & - \\
\hline
\end{tabular}

Abbreviation: SD, Standard deviation.

Notes: The $p$-values relate to the comparison between the two groups (standard vs. protocol group at initial evaluation). Semmes-Weinstein monofilaments test sensory detection thresholds. $\mathrm{Hz}=$ hertz.

The values in bold are abnormal values. There were no significant differences between the ulnar innervated fingers (little) and the median nerve innervated fingers (thumb and index).

The significant differences between the groups at initial evaluation were in the ratio of involved/uninvolved static and moving 2-point discrimination of the index finger and the moving 2-point discrimination of the little finger. The standard group had discrimination better than the treatment protocol group.

Vibration was documented as normal or abnormal. Vibration was also not compared with the uninjured side but rather to normative values.

immobilization or sensory deprivation needs to be present to cause a clinically measureable loss in the wrist. Furthermore, at 3 months the deficit improved and there was no difference between the two treatment groups, so in summary, the clinical importance of this protocol in improving proprioception remains unclear and this study does not support its use.

Part of the difficulty, we encountered, was in our ability to understand and then evaluate and treat proprioception. Our evaluation of proprioception consisted of first positioning the uninjured hand and then having the patient bring the injured side to the same position with eyes closed. The same was then done moving the injured hand first. As stated, since we could not compare sides, it is possible that we were not evaluating proprioception correctly. Although evaluating the uninjured side and injured side separately is certainly a distinct evaluation, we were unsure as to how these evaluations contrasted because 
Table 5 Wrist motion at 6 weeks and 3 months comparison between the groups

\begin{tabular}{|c|c|c|c|c|c|c|c|}
\hline & $\begin{array}{l}\text { Standard } \\
\text { rehabilitation } \\
6 \mathrm{wk}, n=13\end{array}$ & $\begin{array}{l}\text { Standard } \\
\text { rehabilitation } \\
3 \mathrm{mo}, n=13\end{array}$ & $\begin{array}{l}p \text {-Value } \\
\text { standard }^{\text {a }}\end{array}$ & $\begin{array}{l}\text { Protocol } \\
\text { rehabilitation } \\
6 w k, n=10\end{array}$ & $\begin{array}{l}\text { Protocol } \\
\text { rehabilitation } \\
3 \mathrm{mo}, n=10\end{array}$ & $\begin{array}{l}p \text {-Value } \\
\text { protocol }^{a}\end{array}$ & $\begin{array}{l}p \text {-Value } \\
(+)\end{array}$ \\
\hline $\begin{array}{l}\text { Wrist ulnar deviation } \\
\text { involved/uninvolved }\end{array}$ & $0.60(0.18)$ & $0.66(0.26)$ & 0.50 & $0.47(0.17)$ & $0.79(0.20)$ & 0.002 & 0.02 \\
\hline $\begin{array}{l}\text { Wrist radial } \\
\text { deviation } \\
\text { involved/uninvolved }^{\text {b }}\end{array}$ & $0.63(0.24)$ & $0.71(0.28)$ & 0.52 & $0.54(0.19)$ & $0.89(0.24)$ & 0.001 & 0.04 \\
\hline $\begin{array}{l}\text { Wrist flexion } \\
\text { involved/uninvolved }\end{array}$ & $0.39(0.14)$ & $0.67(0.14)$ & 0.003 & $0.39(0.12)$ & $0.76(0.17)$ & 0.001 & 0.30 \\
\hline $\begin{array}{l}\text { Wrist extension } \\
\text { involved/uninvolved }\end{array}$ & $0.59(0.18)$ & $0.73(0.11)$ & 0.07 & $0.49(0.38)$ & $0.83(0.17)$ & 0.001 & 0.30 \\
\hline $\begin{array}{l}\text { Wrist supination } \\
\text { involved/uninvolved }\end{array}$ & $0.68(0.14)$ & $0.73(0.16)$ & 0.40 & $0.65(0.26)$ & $0.85(0.17)$ & 0.02 & 0.18 \\
\hline $\begin{array}{l}\text { Wrist pronation } \\
\text { involved/uninvolved }\end{array}$ & $0.99(0.03)$ & $1.00(0.00)$ & 0.30 & $0.85(0.23)$ & $0.99(0.05)$ & 0.04 & 0.30 \\
\hline
\end{tabular}

Notes: $(+)$ p-value refers to comparison of the groups in the amount of change from $0-3$ mo. The significant values are marked by bold facing. ${ }^{a} p$-value compares change from initial evaluation to evaluation at 3 mo within the group. Most movements improved significantly between the 2 time periods ( 6 wk and 3 mo postsurgery) in both groups.

Table 6 Proprioception testing at initial evaluation, 6 weeks and 3 months postoperative comparison between the groups

\begin{tabular}{|l|l|l|l|l|l|}
\hline & $\begin{array}{l}\text { Standard } \\
\text { rehabilitation } \\
\text { initial }(\boldsymbol{n}=\mathbf{3 1})\end{array}$ & $\begin{array}{l}\text { Standard } \\
\text { rehabilitation } \\
\mathbf{3} \text { mo }\end{array}$ & $\begin{array}{l}\text { Protocol } \\
\text { rehabilitation } \\
\text { initial }(\boldsymbol{n}=\mathbf{2 9})\end{array}$ & $\begin{array}{l}\text { Protocol } \\
\text { rehabilitation } \\
\mathbf{3} \text { mo }\end{array}$ & $\begin{array}{l}p \text {-Value } \\
11(16.7)\end{array}$ \\
\hline $\begin{array}{l}\text { Proprioception thumb } \\
\text { involved } n \text { (\% abnormal) }\end{array}$ & $12(38.7)$ & $9(20.0)$ & $9(40.9)$ & $5(33.3)$ & 0.65 \\
\hline $\begin{array}{l}\text { Proprioception fingers all } \\
\text { involved } n \text { (\% abnormal) }\end{array}$ & $12(40.0)$ & $7(24.1)$ & $2(7.4)$ & $1(4.5)$ & 0.28 \\
\hline $\begin{array}{l}\text { Proprioception wrist } \\
\text { involved } n \text { (\% abnormal) }\end{array}$ & $6(19.4)$ & $3(20)$ & 10 & \\
\hline
\end{tabular}

Note: All finger measurements were used for proprioception of fingers. p-Value evaluates the difference from 0 to 3 months between the two groups (protocol and standard treatment groups). There were no significant associations.

both tests for proprioception (first moving the injured side, first moving the uninjured side) required input and output from both sides. We, therefore, analyzed them as separate tests (not as compared with each other: involved/uninvolved). In general, it is not completely clear, what neurological pathways are involved in wrist proprioception and it is possible that this study was unable to demonstrate differences between the treatment protocols not only because we were underpowered, but also because our testing is inadequate to evaluate true function. ${ }^{34,35}$ Karagiannopoulos et al evaluated active joint position sense and found it to be sensitive to change following DRF. ${ }^{36}$

Many of the sensorimotor tests do not take into account differences in side dominance. Recently, studies have demonstrated that hand dominance has a profound effect on the results of the DASH score. ${ }^{37,38}$ The inability to compare with norms related to hand dominance might have affected our results. Further study is necessary to clarify the effect of hand dominance on other functional tests.

Vibration testing demonstrated increased sensitivity to vibration in over $20 \%$ of the patients at initial evaluation.
Furthermore, this test did not seem to change in either treatment group. Some studies have discussed the use of vibration as treatment for edema, but it is possible that the occurrence of edema (as in the postoperative state) actually affects sensitivity to vibration. ${ }^{39}$ Mridha et al evaluated the effect of fluid in the tissues on mechanical pulse wave propagation. ${ }^{40}$ It is not clear, why the sense of vibration remained abnormal throughout the period of the study. Further study is necessary to better understand the relevance of vibration in the healing upper extremity.

Temperature was normal throughout the period of the study, possibly because it is logical that immobilization would have no effect on temperature input (sensation).

DRF are the most common cause of CRPS in the upper extremity. ${ }^{41,42}$ The beginning of, or tendency toward CRPS was more common in the standard therapy group. No patients actually developed CRPS. This may be due to very detailed follow-up and aggressive therapy, when CRPS was suspected. Though, this study was not aimed at evaluation CRPS development and clearly, we were underpowered for this 
evaluation, we believe that this treatment protocol has the potential to prevent the development of CRPS, since essentially, we are connecting the brain to the limb at a very early stage of recovery. The treating therapists had the impression that the patients treated with the protocol had better and earlier return to function and again, though this was not substantiated using most of the tests, it is possible that our testing is lacking, and not that the differences do not exist.

To date, prevention of CRPS rests on our ability to diagnose and treat it early, perhaps, we can prevent its occurrence altogether using this or similar protocols. ${ }^{43,44}$ Further study is necessary to evaluate the utility of our protocol in CRPS.

Limitations: Assessment of outcomes after hand and wrist surgery is important to be able to improve results and to communicate regarding our treatment of wrist conditions. While we have clear radiographic guidelines (such as intraarticular step-off in distal radius fractures), evaluating true functional outcome is difficult. Partially at least, the difficulty stems from the effect of multiple variables, not all of them easily measured on hand and wrist function. Furthermore, function itself is composed of multiple components, some of them difficult to quantify and qualify. Outcomes, following surgery for DRF, will be dependent on the quality of surgical correction, the postoperative therapeutic protocol, and the patient's adherence to it, as well as patient characteristics. ${ }^{35,45}$ As stated, though we felt that patients being treated with the sensorimotor protocol improved faster, the difference was not statistically significant in many of the parameters that were evaluated. The observation by the treating therapists that patients used their hands faster and better needs to be examined scientifically and systematically. Our minimal significant findings may be due to the complexity of function and its evaluation, that is, though we measured a relatively wide range of functions, we did not encompass some important aspects of function that were indeed influenced by the protocol but were not included in our testing. There are some studies that have shown minimal association between functional tests, such as the DASH score and wrist flexion and true function. ${ }^{46}$ We believe a better test/s of function should be devised to incorporate both hands in the task/s as well as to take into account sensory (afferent) function and motor (efferent) function, while correcting for patient-related factors such as anxiety. It is also possible that we were underpowered to detect some of the differences.

In summary, we trialed a treatment protocol based on sensorimotor input. This study supports its use in DRF. Our clinical impression was that it promoted a significant improvement in functional outcome, though there was a discrepancy between the perceived function and our outcome measures. We believe, this protocol may also have the potential to improve our rehabilitation of other injuries and conditions including CRPS. More study is necessary to better evaluate its utility, and to better understand sensorimotor neurological processes in the wrist, and how to evaluate them.

\section{Funding}

None.

\section{Conflict of Interest}

None.

\section{References}

1 Edgerton VR, Courtine G, Gerasimenko YP, et al. Training locomotor networks. Brain Res Brain Res Rev 2008;57(01):241-254

2 Guillery RW. Anatomical pathways that link perception and action. Prog Brain Res 2005;149:235-256

3 Baert IA, Mahmoudian A, Nieuwenhuys A, et al. Proprioceptive accuracy in women with early and established knee osteoarthritis and its relation to functional ability, postural control, and muscle strength. Clin Rheumatol 2013;32(09):1365-1374

4 Biel A, Dudziński K. Rehabilitation outcome in patients recovering from reconstruction of the anterior cruciate ligament: a preliminary report. Ortop Traumatol Rehabil 2005;7(04): 401-405

5 Rios JL, Gorges AL, dos Santos MJ. Individuals with chronic ankle instability compensate for their ankle deficits using proximal musculature to maintain reduced postural sway while kicking a ball. Hum Mov Sci 2015;43:33-44

6 Schiftan GS, Ross LA, Hahne AJ. The effectiveness of proprioceptive training in preventing ankle sprains in sporting populations: a systematic review and meta-analysis. J Sci Med Sport 2015;18 (03):238-244

7 Smith TO, King JJ, Hing CB. The effectiveness of proprioceptivebased exercise for osteoarthritis of the knee: a systematic review and meta-analysis. Rheumatol Int 2012;32(11):3339-3351

8 da Silva KN, Teixeira LE, Imoto AM, Atallah AN, Peccin MS, Trevisani VF. Effectiveness of sensorimotor training in patients with rheumatoid arthritis: a randomized controlled trial. Rheumatol Int 2013;33(09):2269-2275

9 Hagert E. Proprioception of the wrist joint: a review of current concepts and possible implications on the rehabilitation of the wrist. J Hand Ther 2010;23(01):2-17

10 Aimonetti JM, Morin D, Schmied A, Vedel JP, Pagni S. Proprioceptive control of wrist extensor motor units in humans: dependence on handedness. Somatosens Mot Res 1999;16(01):11-29

11 Marini F, Squeri V, Morasso P, Masia L. Wrist Proprioception: Amplitude or Position Coding? Front Neurorobot 2016;10:13

12 Patterson RW, Van Niel M, Shimko P, Pace C, Seitz WH Jr. Proprioception of the wrist following posterior interosseous sensory neurectomy. J Hand Surg Am 2010;35(01):52-56

13 Karagiannopoulos C, Michlovitz S. Rehabilitation strategies for wrist sensorimotor control impairment: From theory to practice. J Hand Ther 2016;29(02):154-165

14 Röijezon U, Faleij R, Karvelis P, Georgoulas G, Nikolakopoulos G. A new clinical test for sensorimotor function of the hand - development and preliminary validation. BMC Musculoskelet Disord 2017;18(01):407

15 Bearne LM, Coomer AF, Hurley MV. Upper limb sensorimotor function and functional performance in patients with rheumatoid arthritis. Disabil Rehabil 2007;29(13):1035-1039

16 Park JH, Kim D, Park H, Jung I, Youn I, Park JW. The effect of triangular fibrocartilage complex tear on wrist proprioception. J Hand Surg Am 2018. Doi: 10.1016/j.jhsa.2018.01.022

17 Leung PC. Sensory recovery in transplanted toes. Microsurgery 1989;10(03):242-244

18 Fedrizzi E, Pagliano E, Andreucci E, Oleari G. Hand function in children with hemiplegic cerebral palsy: prospective follow-up and functional outcome in adolescence. Dev Med Child Neurol 2003;45(02):85-91

19 Connell LA, Lincoln NB, Radford KA. Somatosensory impairment after stroke: frequency of different deficits and their recovery. Clin Rehabil 2008;22(08):758-767

20 Herold F, Orlowski K, Börmel S, Müller NG. Cortical activation during balancing on a balance board. Hum Mov Sci 2017; 51:51-58 
21 Herwig A, Prinz W, Waszak F. Two modes of sensorimotor integration in intention-based and stimulus-based actions. Q J Exp Psychol (Hove) 2007;60(11):1540-1554

22 Vlaar MP, Solis-Escalante T, Dewald JPA, et al; 4D-EEG consortium. Quantification of task-dependent cortical activation evoked by robotic continuous wrist joint manipulation in chronic hemiparetic stroke. J Neuroeng Rehabil 2017;14(01):30

23 Taube W, Mouthon M, Leukel C, Hoogewoud HM, Annoni JM, Keller M. Brain activity during observation and motor imagery of different balance tasks: an fMRI study. Cortex 2015;64:102-114

24 Wilk KE, Macrina LC. Nonoperative and postoperative rehabilitation for glenohumeral instability. Clin Sports Med 2013;32(04): 865-914

25 Valdes K, Naughton N, Algar L. Sensorimotor interventions and assessments for the hand and wrist: a scoping review. J Hand Ther 2014;27(04):272-285, quiz 286

26 Avanzino L, Pelosin E, Abbruzzese G, Bassolino M, Pozzo T, Bove M. Shaping motor cortex plasticity through proprioception. Cereb Cortex 2014;24(10):2807-2814

27 Kavounoudias A, Roll JP, Anton JL, Nazarian B, Roth M, Roll R. Proprio-tactile integration for kinesthetic perception: an fMRI study. Neuropsychologia 2008;46(02):567-575

28 Wollstein R, Michael D, Harel H. A protocol for evaluation and rehabilitation of distal radius fractures using sensorimotor input: a case series. J Hand Surg Asian Pac Vol 2017;22(02):150-155

29 Li XM, Yang Y, Hou Y, et al. Diagnostic accuracy of three sensory tests for diagnosis of sensory disturbances. J Reconstr Microsurg 2015;31(01):67-73

30 Jerosch-Herold C. A study of the relative responsiveness of five sensibility tests for assessment of recovery after median nerve injury and repair. J Hand Surg [Br] 2003;28(03):255-260

31 Van Dokkum LEH, Mottet D, Laffont I, et al. Kinematics in the brain: unmasking motor control strategies? Exp Brain Res 2017; 235(09):2639-2651

32 Merians AS, Poizner H, Boian R, Burdea G, Adamovich S. Sensorimotor training in a virtual reality environment: does it improve functional recovery poststroke? Neurorehabil Neural Repair 2006;20(02):252-267

33 Enke AM, Poskey GA. Neuromuscular re-education programs for musicians with focal hand dystonia: a systematic review. Med Probl Perform Art 2018;33(02):137-145

34 Gutiérrez-Espinoza H, Rubio-Oyarzún D, Olguín-Huerta C, Gutiérrez-Monclus R, Pinto-Concha S, Gana-Hervias G. Supervised physical therapy vs home exercise program for patients with distal radius fracture: A single-blind randomized clinical study. J Hand Ther 2017;30(03):242-252

35 James MA, Bagley A, Vogler JB IV, Davids JR, Van Heest AE. Correlation between standard upper extremity impairment measures and activity-based function testing in upper extremity cerebral palsy. J Pediatr Orthop 2017;37(02):102-106

36 Karagiannopoulos C, Sitler M, Michlovitz S, Tucker C, Tierney R. Responsiveness of the active wrist joint position sense test after distal radius fracture intervention. J Hand Ther 2016;29(04): 474-482

37 Lutsky K, Kim N, Medina J, Maltenfort M, Beredjiklian PK. Hand dominance and common hand conditions. Orthopedics 2016;39 (03):e444-e448

38 Kachooei AR, Moradi A, Janssen SJ, Ring D. The influence of dominant limb involvement on DASH and QuickDASH. Hand (NY) $2015 ; 10(03): 512-515$

39 Leduc A, Lievens P, Dewald J. The influence of multidirectional vibrations on wound healing and on regeneration of blood- and lymph vessels. Lymphology 1981;14(04):179-185

40 Mridha M, Odman S, Oberg PA. Mechanical pulse wave propagation in gel, normal and oedematous tissues. J Biomech 1992;25 (10):1213-1218

41 Wang JH, Sun T. Comparison of effects of seven treatment methods for distal radius fracture on minimizing complex regional pain syndrome. Arch Med Sci 2017;13(01):163-173

42 Puchalski P, Zyluk A. Complex regional pain syndrome type 1 after fractures of the distal radius: a prospective study of the role of psychological factors. J Hand Surg [Br] 2005;30(06): 574-580

43 Dijkstra PU, van der Schans CP, Geertzen JH. Risk perception of developing complex regional pain syndrome I. Clin Rehabil 2003; 17(04):454-456

44 Dilek B, Yemez B, Kizil R, et al. Anxious personality is a risk factor for developing complex regional pain syndrome type I. Rheumatol Int 2012;32(04):915-920

45 Niekel MC, Lindenhovius AL, Watson JB, Vranceanu AM, Ring D. Correlation of DASH and QuickDASH with measures of psychological distress. J Hand Surg Am 2009;34(08):1499-1505

46 Bot AG, Souer JS, van Dijk CN, Ring D. Association between individual DASH tasks and restricted wrist flexion and extension after volar plate fixation of a fracture of the distal radius. Hand (NY) 2012;7(04):407-412 